\title{
Evapotranspiration in a Subtropical wetland savanna using low-cost Lysimeter, Eddy Covariance and Modeling approaches
}

\author{
Amartya Saha ${ }^{1}$, Elizabeth Boughton ${ }^{1}$, Haoyu Li ${ }^{1}$, Gregory Sonniér ${ }^{1}$, Nuria \\ Gomez-Casanovas $^{2}$, Nic McMillan ${ }^{1}$, and Xukai Zhang ${ }^{1}$ \\ ${ }^{1}$ Archbold Biological Station \\ ${ }^{2}$ University of Illinois Urbana-Champaign Department of Crop Sciences
}

February 25, 2022

\begin{abstract}
Evapotranspiration (ET) constitutes the largest loss of water from subtropical grassland and wetland ecosystems, yet data in much of the world have high uncertainty at the landscape scale as there is little information on plant water use. Additionally, anthropogenic alterations to grasslands are a major threat globally and alter ecosystem water use, but the impact of these changes is often unquantified. A major reason for this is the complexity and expense of field-based ET quantification methods such as agricultural lysimeters and eddy covariance systems. Accurate measurements of ET are critical for sustainable water management. This study developed two different low-cost lysimeters - weighing-type and water level based, to measure ET under controlled conditions for single species as well as mixed grassland and wetland communities. Lysimeters were placed in an open sided shadehouse with a transparent roof to exclude rainfall. ET values were then compared with (i) Actual ET measurements from an eddy covariance tower onsite, (ii) vapor transport-based ET models - FAO Penman-, Modified Turc and Abtew Simple Radiation models, and (iii) ET data from the Florida Automated Weather Network. Both weighing-type and water level lysimeters showed seasonal patterns and annual magnitudes similar to the other ET methods. Annual ET measurements from weighing-type lysimeters (881-1278 $\mathrm{mm}$ for four plant species, $n=5$ per species, 20 in total) and water level lysimeters (1085 mm, plant community average, $n=31$ ) were similar to model estimates (1000-1200mm). Actual ET from eddy covariance was $722 \mathrm{~mm}$ for ten months (missing data for February and March), while lysimeter measurements for the dominant grass Paspalum notatum was $885 \mathrm{~mm}$ for the same 10 months. Low-cost lysimeters can inform regional ET models/remote sensing data lacking field validation and thus are potentially useful for water resources and ecosystem management in data-poor regions of the world.
\end{abstract}

\section{Hosted file}

Evapotranspiration_LYSIMETERS_EDDYFLUX_MODELS in a Subtropical grassland_Saha_et_al_MAJOR_Rev.docx available at https://authorea.com/users/462264/articles/557737-evapotranspiration-ina-subtropical-wetland-savanna-using-low-cost-lysimeter-eddy-covariance-and-modelingapproaches 


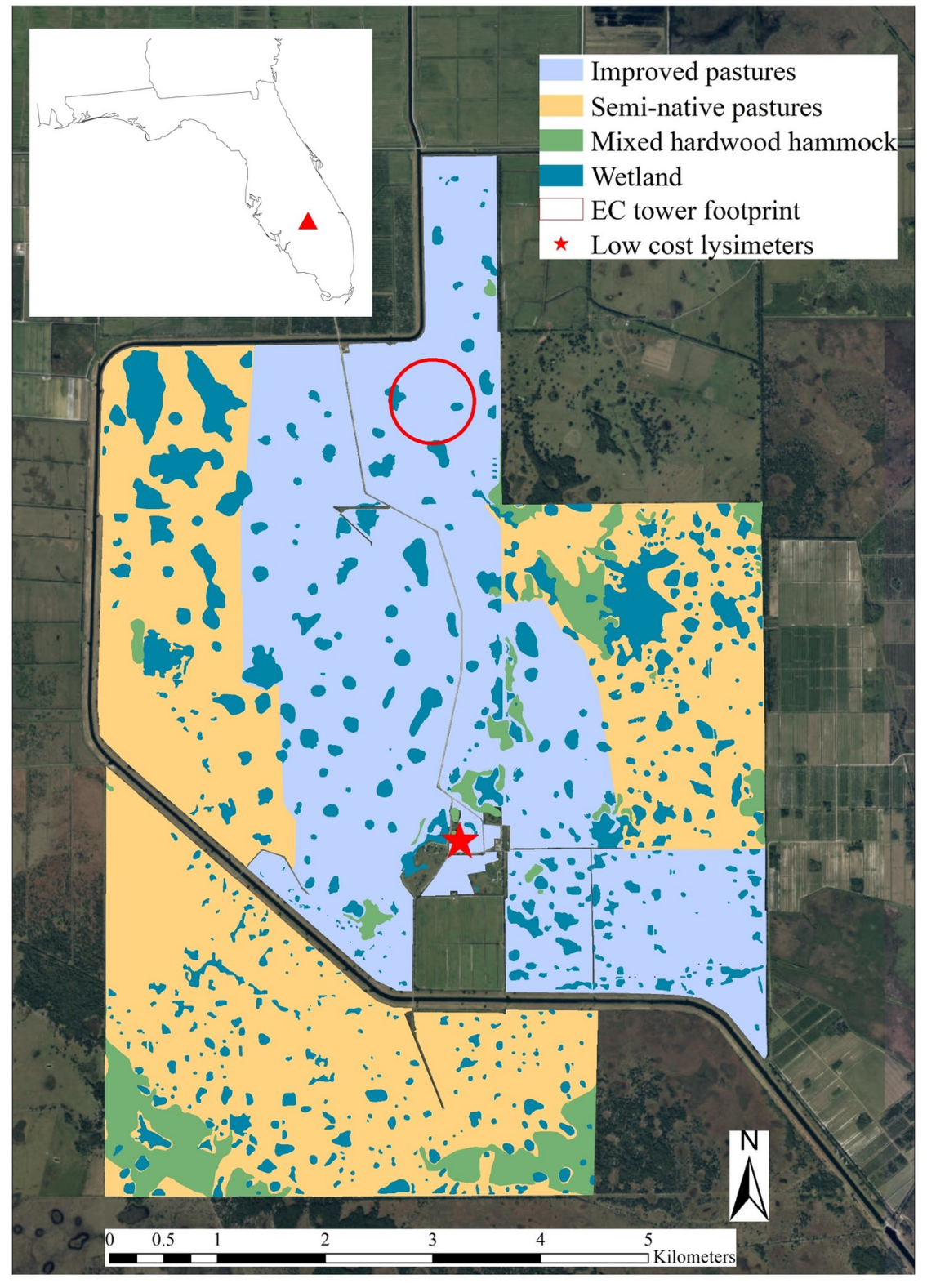



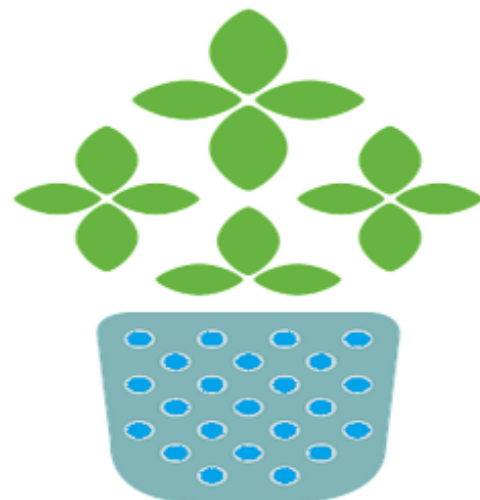

WT (a)



WL (a)


WT (b)

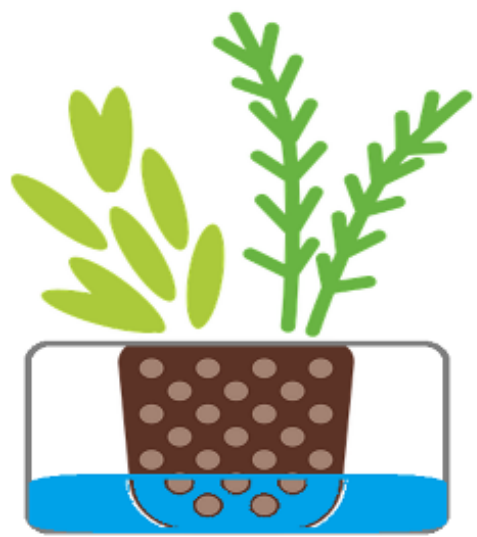

$W L(b)$





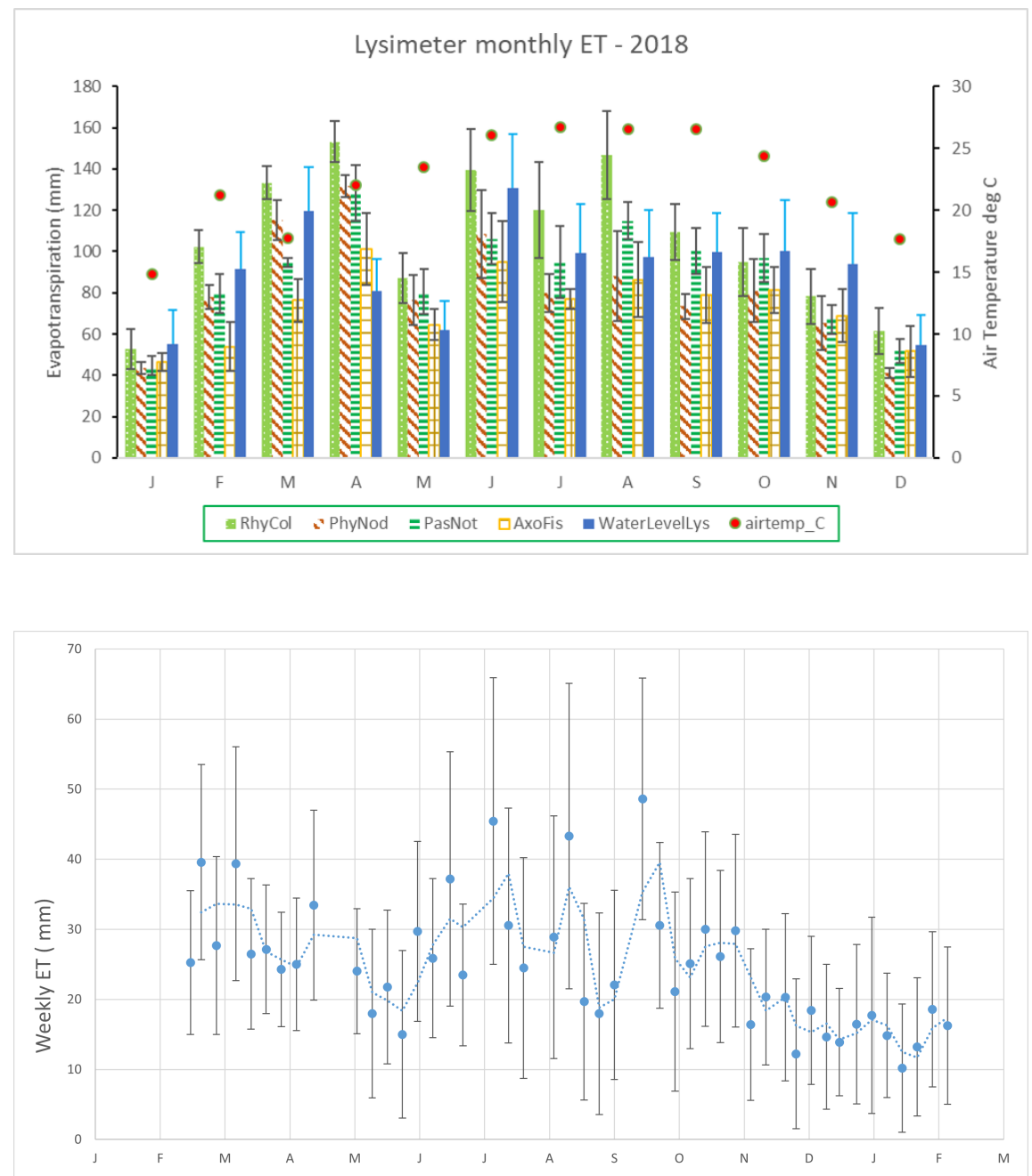

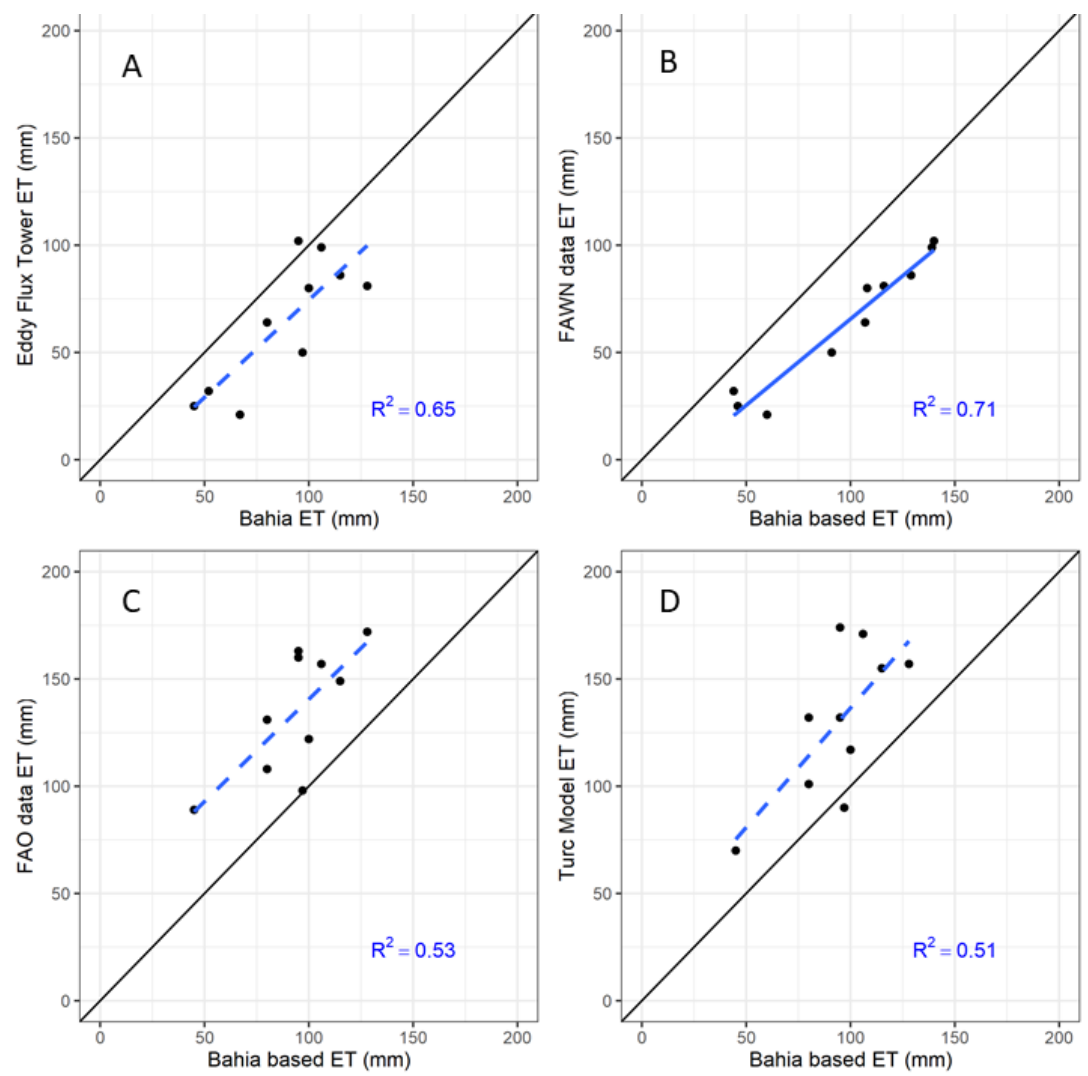

